\section{COVID-19: A unique opportunity for population health to align with nursing schools to help vulnerable populations at risk of adverse}

\section{outcomes}

\author{
Eileen Haley, MSN, RN., Victoria Harris, MPH., Parag \\ Agnihotri, MD., Jamie Kwak and Ming Tai-Seale, PhD, MPH*
}

Population Health Services, Information Services, and Department of Family Medicine, UC San Diego Health System, USA

\section{Introduction}

COVID-19 created a public health crisis shutting down many normal day-to-day activities and adversely affecting life, as we know it. Not only did this affect vulnerable, senior populations and people with poorly managed diabetes and hypertension [1-4], it displaced nursing students from clinical experiences putting them at risk of not graduating. Given the projected shortages of RNs in 2030, in California alone of 44,500 FTEs [5], this delay would have added a ripple effect increasing already dire predictions. This displacement created an emergency and with the aid of the Board of Registered Nursing, Assembly Bill 2288 [6] passed allowing student nurse clinical experience requirements to be revised to help meet graduation requirements.

UC San Diego Health Population Health Services Organization (PHSO) applies a model of population health [7] that strives to address patients' health needs at all points along the continuum of care, including the community setting, by increasing patient participation and engagement and targeting interventions created a synergistic opportunity for cross collaboration with nursing schools.

In April 2020, the Board of Registered Nursing informed us of their approval of our plan for a computer-assisted telephonic wellness outreach program. With the help of some key stakeholders, PHSO was able to engage three nursing schools to support this telephonic outreach effort. The initial program started with nursing students telephonically outreaching to vulnerable, high-risk seniors, then two additional programs, shortly thereafter were added targeting patients with known poor diabetes or hypertension disease management.

\section{More Information}

*Address for Correspondence:

Ming Tai-Seale, PhD, Professor and Vice Chair of Research, UC San Diego School of Medicine Department of Family Medicine, Director of Research and Learning, UC San Diego Health Population Health Services Organization, Director of Outcomes Analysis and Scholarship, UC San Diego Health Information Services, USA, Email: mtaiseale@health.ucsd.edu

\section{Submitted: January 15, 2021}

Approved: January 28, 2021

Published: February 01, 2021

\begin{abstract}
How to cite this article: Haley E, Harris V, Agnihotri P, Kwak J, Tai-Seale M. COVID-19: A unique opportunity for population health to align with nursing schools to help vulnerable populations at risk of adverse outcomes. Clin J Nurs Care Pract. 2021; 5: 001-002.
\end{abstract}

DOI: 10.29328/journal.cjncp.1001029

Copyright: @ 2021 Haley E, et al. This is an open access article distributed under the Creative Commons Attribution License, which permits unrestricted use, distribution, and reproduction in any medium, provided the original work is properly cited.

D) Check for updates

OPEN ACCESS

\section{Methods}

For the Wellness Program focusing on seniors, the inclusion criteria include patients attributed to our Medicare Fee for Service Accountable Care Organization, and with a general risk score of 11 or greater. The risk score is a UCSD homegrown metric that is built into the electronic health record that accounts for a number of risk factors inclusive of frequent emergency department and hospital utilization, elderly, comorbidities including cancer, diabetes, and depression. The target population based on the inclusion criteria totaled 16,000 patients, residing in north, east and central San Diego Counties and Imperial Valley. The onboarding of nursing students included didactic training on population health, social determinants of health $(\mathrm{SDoH})$, importance of medical management, evidenced based patient reported outcomes built into the medical record with real time process plan for any emergent social or medical concerns to be escalated to our case management team; role-play for motivational interviewing techniques. The nursing students were setup on site and adhered to pandemic precautions (mask wearing, hand hygiene and social distancing). Daily education and rounding included pre and post conferences to ensure reflective practice, along with onsite instructor and a dedicated PHSO registered nurse and social work for support. 
This clinical operational and educational program followed strict ethics guidelines. No protected health information on individuals is present in any reports.

Eligible patients for the Wellness Program for patients with poor hypertension and diabetes management included all patients with a UCSD primary care provider who had a history of poorly managed hypertension or diabetes. The education included didactic segment on $\mathrm{SDoH}$ and overview of the specific disease and nursing implications, along with education on PHSO program offerings and standard documentation with escalations back to the PHSO team. PHSO programs offerings included integrated digital remote patient monitoring tools (blood pressure cuff and/or glucometer), medication optimization with a pharmacist, and behavioral health coaching and texting for patients to select from one or all programs to optimize self-care. The nursing students were asked to engage patients in mainly Agile ${ }^{\mathrm{TM}}$ a health coaching and texting program offered by PHSO to minimize length of the call, with the plan that PHSO nurses would follow up with the interested patients to enroll in other program options. Daily onsite process and staff availability is standard on each day.

\section{Results}

The nursing students started with PHSO in April 2020, in the middle of their semester, so they could have been in an acute medical/surgical inpatient setting, leadership or community health rotation. Table 1 shows out of 45 students 93.33\% believed the rotation was applicable, regardless of the semester they were in, to their clinical practice. For $82.22 \%$ of them, this was their first experience with telephonic outreach and $91.11 \%$ stated that they felt more comfortable and better prepared to speak with patients on a nursing level.

Some nursing students provided free text responses to express their views about their experience:

"Telehealth enables us to reach out to the community, find out their health needs and help them find solutions to their concerns."

\section{"The importance of outreach."}

"Communication, charting and time management."

\section{"Learned how to listen to patients"}

Instructor feedback was positive, with some constructive feedback related to reducing length of script for telephone

\begin{tabular}{|c|c|c|c|}
\hline & Yes & No & Other \\
\hline $\begin{array}{c}\text { Did you find this rotation applicable to your current } \\
\text { rotation/clinical practice? }\end{array}$ & $93.33 \%$ & $6.67 \%$ & $0.00 \%$ \\
\hline $\begin{array}{l}\text { Is this your first experience with Telehealth/ } \\
\text { Telephonic Patient Outreach? }\end{array}$ & $82.22 \%$ & $15.56 \%$ & $2.22 \%$ \\
\hline $\begin{array}{c}\text { Do you feel more comfortable and better prepared } \\
\text { to converse with patients on a nursing level? }\end{array}$ & $91.11 \%$ & $2.22 \%$ & $6.67 \%$ \\
\hline
\end{tabular}

calls and setting clear expected telephone call targets for each student. Instructor responses to the survey question, what did you learn from this rotation? included:

"Exciting, highlyinformative and a greatlearning experience".

"Students learned effective communication, collaboration and documentation".

"How important it is to care for patients outside the hospital setting."

\section{Discussion and conclusions}

Feedback from nursing students and instructors suggest that programs like these are valuable during pandemics and beyond. Nurses serve a unique role in the community, according to a Gallup Poll nurses have been ranked as the most trusted profession in the United States for the last 18 years [8]. Social determinants and inequity are driving disease and adversely impact people, communities and payers [9]. Collaboration with nursing schools enable healthcare organizations to offer alternate clinical experiences aligned with a Focus on Culture of Health [10], value based payment, and efforts to address inequity and the need for providers to collaborate with nurses to develop holistic care plans that go beyond the medical realm and include the voice and the needs of the patient.

More opportunity exists to further fine-tune nursing school curriculum with population health contents for greater student learning and alignment.

\section{References}

1. Armitage R, Nellums LB. COVID-19 and the consequences of isolating the elderly. Lancet Public Health. 2020; 5: e256.

PubMed: https://pubmed.ncbi.nlm.nih.gov/32199471/

2. Liu K, Chen Y, Lin R, Han K. Clinical features of COVID-19 in elderly patients: A comparison with young and middle-aged patients. J Infect. 2020; 80: e14-e18. PubMed: https://pubmed.ncbi.nlm.nih.gov/32171866/

3. Wu C, Chen X, Cai Y, Xia J, Zhou X, et al. Risk Factors Associated With Acute Respiratory Distress Syndrome and Death in Patients With Coronavirus Disease 2019 Pneumonia in Wuhan, China. JAMA Intern Med. 2020; 180: 934-943. PubMed: https://pubmed.ncbi.nlm.nih.gov/32167524/

4. Steinman MA, Perry L, Perissinotto CM. Meeting the Care Needs of Older Adults Isolated at Home During the COVID-19 Pandemic. JAMA Intern Med. 2020; 180: 819-820.

PubMed: https://pubmed.ncbi.nlm.nih.gov/32297903/

5. U.S. Department of Health and Human Services HRaSA, National Center for Health Workforce Analysis,. National and Regional Supply and Demand Projections of the Nursing Workforce: 2014-2030,. In. Rockville, Maryland. 2017.

6. California State Assembly. Assembly Bill No. 2288 Nursing programs: state of emergency,. In. Sacremento, California 2020.

7. Kindig D, Stoddart G. What is population health? Am J Public Health. 2003; 93: 380-383.

PubMed: https://pubmed.ncbi.nlm.nih.gov/12604476/

8. Reinhart R. Nurses Continue to Rate Highest in Honesty, Ethics. 2020

9. Kurani SS, McCoy RG, Lampman MA, et al. Association of Neighborhood Measures of Social Determinants of Health With Breast, Cervical, and Colorectal Cancer Screening Rates in the US Midwest. JAMA Netw Open. 2020; 3: e200618. PubMed: https://pubmed.ncbi.nlm.nih.gov/32150271/

10. Robert Wood Johnson Foundation. Building a Culture of Health. 2019. https://www.rwjf.org/en/how-we-work/building-a-culture-of-health.html 